\title{
A GEOCONSERVAÇÃO SOB A ÓTICA LEGISLATIVA: UMA ANÁLISE COMPARATIVA DE LEIS NACIONAIS E INTERNACIONAIS SOBRE A PROTEÇÃO DO PATRIMÔNIO GEOLÓGICO
}

\author{
GEOCONSERVATION UNDER THE LEGISLATIVE OPTICAL: A COMPARATIVE ANALYSIS OF \\ NATIONAL AND INTERNATIONAL LAWS ON THE PROTECTION OF GEOLOGICAL HERITAGE
}

Introdução
Metodologia
Abordagens legislativas
Grã-Bretanha
Espanha
Portugal
Brasil
Discussão dos resultados
Conclusões
Agradecimentos
Referências

Laura Cristina DIAS ${ }^{1}$, Gilda Carneiro FERREIRA ${ }^{2}$

${ }^{1}$ Programa de Pós-Graduação em Geociências e Meio Ambiente. UNESP - Rio Claro, Email: laura_cdias@yahoo.com.br

${ }^{2}$ UNESP - Rio Claro, IGCE, Departamento de Geologia Aplicada. Email: gildacf@rc.unesp.br

RESUMO - Geoconservação é um conceito recente, que se refere à proteção de importantes exemplares da geodiversidade. Proteger determinados elementos geológicos é importante e necessário, uma vez que contêm importantes informações sobre o passado evolutivo de nosso planeta. Este é um tema que vem ganhando cada vez mais espaço no meio geológico; paralelamente, a proteção legal do patrimônio geológico vem sendo contemplada na legislação de muitos países, principalmente europeus. Este trabalho traz uma análise comparativa entre as leis brasileiras e as leis de alguns países (Grã-Bretanha, Espanha e Portugal), no que tange à proteção do patrimônio geológico. Para esta finalidade, foi realizado extenso levantamento bibliográfico sobre o assunto, bem como consulta às legislações nacionais e internacionais que fazem referência à proteção da vertente abiótica da natureza. Verificou-se que a legislação internacional vem abordando este tema, com a definição de conceitos essenciais e previsão de leis e projetos que atendem à proposta de geoconservação. Nesses países, primeiramente é realizado um levantamento de cada sítio geológico, seguido por uma caracterização detalhada, e posterior proposição de medidas de proteção adequadas. Por outro lado, as leis brasileiras estão ainda bastante atrasadas em relação ao assunto, sendo a proteção geológica abordada apenas de maneira indireta, como um substrato da biodiversidade.

Palavras-chave: geoconservação; geodiversidade; legislação.

\begin{abstract}
Geoconservation is a recent concept which refers to the protection of important exemplars of geodiversity. Protecting certain geological elements is important and necessary as they contain important information about the evolutionary past of our planet. This is a topic that is gaining more and more space in geology; in parallel, legal protection of the geological heritage has been contemplated in the legislation of many countries, mainly in Europe. This work presents a comparative analysis between Brazilian laws and the laws of Great Britain, Spain and Portugal, regarding the protection of geological heritage. For this purpose, an extensive bibliographical survey was carried out on the subject, as well as consultation of the national and international laws that refer to the protection of the abiotic nature. It was found that international laws have been addressing this issue, with the definition of essential concepts and predicting laws and projects that meet the geoconservation proposal. In these countries, a survey was conducted on each geological site, followed by a detailed characterization and subsequent proposition of appropriate protective measures. On the other hand, Brazilian laws are still far behind in relation to this subject, and geological protection is only indirectly addressed as a substrate of biodiversity.
\end{abstract}

Keywords: geoconservation; geodiversity; legislation.

\section{INTRODUÇÃO}

A proteção da geodiversidade ou geoconservação é um tema recente dentro das Ciências da Terra, e bastante discutido atualmente. Geodiversidade diz respeito aos elementos abióticos da natureza, como os minerais, fósseis, rochas, processos ativos e paisagens (Pereira, 2010).

Os registros preservados em cada um destes componentes da vertente geológica ajudam a desvendar a história evolutiva da Terra (Brilha, 2005), de modo que sua proteção se faz necessária para salvaguardar tais informações para todos num futuro.

Não são todos os elementos da geodiversidade que necessitam de proteção, apenas aqueles que possuam algum tipo de valor específico (didático, científico, estético, etc.), que sejam mais representativos e singulares como um todo, ou frente às ameaças às quais estão expostos, como o uso excessivo dos recursos naturais, a consequente alteração antropogênica do meio ambiente e a falta de planos de ordenamento territorial (Gray, 2004).

Além de salvaguardar registros importantes 
sobre a história evolutiva da Terra, é necessário proteger tais elementos como um dos requisitos para a declaração de geoparques junto à UNESCO.

De acordo com o Guidelines and Criteria for National Geoparks seeking UNESCO's Assistance to join the Global Geoparks Network (GGN) (Unesco, 2014), que estabelece diretrizes para a chancela de geoparques, um dos requisitos básicos é a proteção dos sítios geológicos - locais onde há um valor específico da geodiversidade. Neste contexto, é possível estabelecer uma relação direta entre a eficiência legal de um país quanto à proteção do patrimônio geológico e a oficialização dos geoparques.

Os geoparques não são categorias de proteção em si, e por esta razão a Unesco (2014) estabelece: “É o Governo do país onde está situado o geoparque que decide sobre o nível e as medidas de proteção dos sítios e afloramentos geológicos”.

Para efetiva proteção destes recursos são necessárias medidas legais que assegurem a sua integridade frente às ameaças que vem sofrendo. Muitos países, já possuem leis específicas que visam proteger os elementos mais relevantes da geodiversidade nacional.

No Brasil, existem alguns instrumentos jurídicos que podem ser utilizados para enquadrar a proteção do patrimônio geológico.

No entanto, as leis nacionais apontam majoritariamente a proteção da biodiversidade, e abordam os recursos abióticos de maneira secundária (Pereira et al., 2008).

Autores como Pereira et al. (2008), Boggiani (2009) e Silva \& Assumpção (2009) trouxeram para discussão a proteção brasileira dos espécimes geológicos, os quais podem ser protegidos apenas de maneira indireta, pois a geodiversidade não é especificamente contemplada na legislação nacional.

Mediante a lacuna existente no ordenamento jurídico brasileiro em relação à proteção da geodiversidade, é de grande importância trazer para discussão a necessidade de criação de leis específicas que venham garantir a proteção do patrimônio geológico e impulsionar a criação de geoparques no país. Sabendo que muitos países, principalmente europeus, já apresentam avanços quanto à proteção da geodiversidade especificamente, este trabalho traz uma análise comparativa das leis nacionais e internacionais no que tange ao assunto.

Para isso, foram escolhidos a Grã-Bretanha, Espanha e Portugal a fim de estabelecer uma comparação com o Brasil em termos de leis de proteção da geodiversidade.

\section{METODOLOGIA}

Para estabelecer uma comparação com as leis brasileiras foram escolhidos os países: GrãBretanha, por ser considerada pioneira em relação à geoconservação; Espanha, que possui um ordenamento jurídico voltado especificamente para a temática em questão; e Portugal, que se destaca em trabalhos acadêmicos na área e que possui uma legislação recente que contempla a proteção dos sítios geológicos. Para obtenção de dados foram realizadas consultas bibliográficas relacionadas à geoconservação, e consultas às leis nacionais e internacionais que possuem instrumentos de proteção ambiental e/ou proteção da geodiversidade.

Procurou-se primeiramente levantar os principais instrumentos legais que fazem referência à geodiversidade e sua proteção, para cada um dos países mencionados.

As principais leis compuseram um quadro comparativo para melhor visualização das disparidades e semelhanças encontradas nas legislações de cada localidade.

\section{ABORDAGENS LEGISLATIVAS}

\section{Grã-Bretanha}

Os países da Grã-Bretanha são pioneiros no que tange à geoconservação, apresentando um cenário avançado frente a outras nações em relação ao tema. Enquanto em muitos países o conceito da geoconservação é relativamente novo, a Grã-Bretanha apresenta estrutura sobre a proteção dos recursos geológicos há mais de 50 anos (Lima, 2008). De um modo geral, a legislação britânica considera separadamente os aspectos bióticos e abióticos no contexto legal, conferindo proteção específica para os sítios geológicos. O Planning Policy Statement 9 (PPS 9) sobre Conservação da Biodiversidade e Conservação Geológica é um documento sobre recomendações às autoridades para a proteção geológica e biológica, elaborado pelo governo britânico. Em 2006 foi atualizado pelo ODPM 
Circular 06/2005, e atualmente está contido no National Planning Policy Framework (DCLG, 2012). Tais documentos apresentam distinção entre biodiversidade e geodiversidade, sendo biodiversidade "a variedade de todas as formas de vida”, e, os lugares de interesse geológico os "lugares que são designados pela sua importância geológica ou geomorfológica”.

As leis voltadas para a conservação da natureza e dos aspectos geológicos remontam de 1949, sendo que desde o século XIX o assunto é centro de discussões (Lima, 2008). A identificação dos sítios geológicos passou a ter uma visão holística de conservação por volta da década de 1980, culminando no estabelecimento de uma proteção jurídica aos Sítios de Especial Interesse Científico (Sites of Special Scientific Interest - SSSIs) (Lima, 2008). A proteção e proposição dos sítios parte, a princípio, da iniciativa governamental, em decorrência da relevância faunística e florística, geológica ou paisagística de uma área e a necessidade de sua proteção (Ellis et al., 2008).

A seleção dos sítios de cunho geológico é de responsabilidade do programa Geological Conservation Review (GCR) criado em 1977, que também elabora uma base de dados com informações dos sítios listados (Lima, 2008). Apenas quando um sítio é aprovado como SSSIs é que ele recebe todo o aparato de proteção legal. Os sítios da GCR não têm proteção legalizada antes de ser notificado como SSSIs (Prosser et al., 2006). O Art. 28 do Wild life and Countryside Act 1981 (United Kingdon, 1981), e no schedule 9 do Countryside and Rights of Way Act 2000 (United Kingdon, 2000), referem-se às disposições relativas à notificação, proteção e gestão dos SSSIs. A aprovação como SSSIs confere alto grau de proteção aos sítios, mas não garante a sua proteção em longo prazo. Inicialmente, os proprietários ou ocupantes da área são formalmente notificados da importância das características abióticas do local, e caso o dono ou ocupante venha a alterar estes recursos sem o consentimento formal encontrado pela Natural England, o mesmo é notificado a corrigir os danos causados, além de ser levado a processos judiciais (Prosser et al., 2006). Conforme previsto na Countryside and Rights of Way Act 2000, também há possibilidade de abordar os danos aos SSSIs causados por terceiros.

A ODPM 06/2005 sobre Conservação Geológica e da Biodiversidade traz na Part I, referências sobre as Áreas de Proteção Especiais e as Potenciais Áreas de Proteção Especiais (SPAs e pSPAs), na qual são previstos planejamentos e envolvimento das autoridades para a proteção da biodiversidade e da geodiversidade. A Part II do mesmo documento faz referência aos SSSIs e sua proteção, prevendo tanto ações de notificações de sítios quanto de planejamento para conservação dos mesmos (United Kingdom, 2005).

O lançamento do GCR apresentou como metas a identificação e descrição dos sítios geológicos mais importantes da Grã-Bretanha, sendo catalogados mais de 3000 sítios ao longo da sua atuação. As informações sobre as descrições dos sítios formam um compilado de 45 volumes, publicados com o título Geological Conservation Review Series, além de estarem disponíveis para acesso através de um banco de dados digital (GCR Database) no endereço www.jncc.defra.gov.uk. Esta é uma atividade muito semelhante àquela apresentada pela SIGEP, no Brasil. O GCR, além de selecionar sítios para sua proteção, também apoiam o estabelecimento e criação de vários geoparques no Grã-Bretanha e conferem suporte a uma série de iniciativas educacionais e geoturísticas (Ellis, 2008).

De acordo com o Guidelines for Selection of Earth Science SSSI (JNCC, 1977) que elabora as diretrizes para seleção dos sítios geológicos, a proteção dos mesmos ocorre de acordo com três características principais de cada sítio: a) Representatividade das características geológicas e fisiográficas; b) Especial interesse dos sítios a nível internacional; c) Elementos excepcionais nacionalmente, que representem a história geológica da Grã-Bretanha.

Para melhor gerenciar os sítios foram especificadas categorias gerais que refletissem, em um primeiro momento, a característica geológica principal do sítio: paleontologia, mineralogia, estratigrafia, dentre outros. Para cada categoria foram criados subgrupos que retratam as características específicas de cada um dentro da área-tema geral. Cada subgrupo ficou sob responsabilidade de um especialista da área 
para ser descrito e caracterizado, sendo que os sítios são regularmente monitorados e reavaliados para refino das informações adquiridas sobre o sítio (Lima, 2008). No entanto, estas não são áreas protegidas com os mesmos intuitos de criação de um geoparque (ou seja, com finalidades geoturísticas), sendo que a visitação apenas é aberta ao público mediante prévia autorização da agência de conservação ou do proprietário quando se tratar de áreas particulares (Ellis et al., 2008).

Outra iniciativa encontrada na Grã-Bretanha são os Regionally Important Geodiversity Sites (RIGS) estabelecidos em 1990, que tem como objetivo a caracterização dos sítios geológicos regionais, diferentemente dos SSSIs, eles não possuem um caráter legal apesar de terem o apoio dos governos locais (UKRIGS, 2009). Muitos planos de gestão das autoridades locais incluem os RIGS no seu planejamento de desenvolvimento local (UKRIGS, 2009). Estes planos possuem políticas para a proteção dos RIGS, e a sua relevância é considerada nas tomadas de decisões de planejamento (Prosser et al., 2006).

Uma proposta mais recente criada em 2002, os Local Geodiversity Action Plans (LGAPs) visam catalogar os sítios geológicos e construir um plano de gerenciamento da geodiversidade a nível local, além de: 1) Identificar, conservar e valorizar os melhores sítios que representam a história geológica da área de cunho científico, educacional, recreativo e cultural; 2) Promover os sítios geológicos e a geoconservação junto à população; 3) Fornecer avaliações da geodiversidade local; 4) Estimular uma política do planejamento local.

Até o ano de 2008 havia 40 LGAPs em andamento, com foco em áreas municipais ou administrativas. Através da Company Geodiversity Action Plans, há uma atenção que também inclui as substâncias minerais da indústria de mineração, onde é prevista a participação das mesmas nas ações implantadas pelo projeto (Haffey, 2008).

Os trabalhos de Ellis et al. (1996) e Prosser et al. (2006) trazem um compilado dos instrumentos legais, comitês e instituições que foram sendo criados ao longo do tempo em relação à proteção do patrimônio geológico da Grã-Bretanha, iniciado na década de 40 do século XX.

\section{Espanha}

A Espanha é um país que vem trabalhando exaustivamente em prol de pesquisas e divulgação das geociências em seu território. Além de instituições de pesquisas acadêmicas estão envolvidos o Instituto Geológico e Mineiro da Espanha (IGME), Comissão do Patrimônio Geológico da Sociedade Geológica da Espanha, Sociedade Espanhola para a Defesa do Patrimônio Geológico e Mineiro (SEDPGYM) e, Sociedade Espanhola de Geologia Ambiental e Ordenamento do Território (SEGAOT).

Desde 1978, com esforços do IGME começaram a ser levantados estudos sobre o patrimônio geológico e geodiversidade da Espanha, principiando o Inventário Nacional de Pontos de Interesse Geológico (Inventario Nacional de Puntos de Interés Geológico conhecido como PIG) com 234 pontos registrados. Após o encerramento das atividades do PIG, iniciou-se em 1989 a elaboração de um projeto de mapeamento geológico do território espanhol juntamente com informações sobre 545 pontos de interesse geológicos previamente identificados (Lima, 2008). Durante os mais de 30 anos desde o início da elaboração do inventário, a temática em questão e os conceitos envolvidos ganharam cada vez mais o interesse da comunidade geológica, resultando em pesquisas, publicações e reconhecimento da geodiversidade em praticamente todo o território espanhol, contribuindo para uma tomada de consciência em relação ao valor do patrimônio geológico por parte da comunidade (García-Cortés \& Carcavilla-Urquí, 2009). O grande alcance atingido pelos estudos das Ciências da Terra também contribuiu para a inclusão dos seus conceitos na legislação espanhola.

Em 2007, foram aprovadas três leis que inovam por abordar geodiversidade e biodiversidade explícita e separadamente, as quais colocam geodiversidade e patrimônio geológico como aspectos específicos da paisagem e preveem a sua proteção. São elas: Ley 5/2007 - Red de Parques Nacionais (LRPN); Ley 45/2007 - Desarollo Sostenible del Medio Rural (LDSMR); Ley 42/2007 - Ley del Patrimonio Natural y de la Biodiversidad (LPNB). As leis são complementares, visto que 
a definição de termos como geodiversidade, geoparque, geoconservação são encontradas na Ley 42/2007 permitindo o bom entendimento e uso dos mesmos termos nas leis: Ley 5/2007 e Ley 45/2007.

A LRPN vigente desde abril de 2007 com última revisão em junho de 2013, estabelece um regime jurídico básico da Rede de Parques Naturais da Espanha. Parques Naturais são definidos por esta lei como "um sistema dirigido para integrar a amostra mais representativa do conjunto de sistemas naturais espanhóis”, sendo os sistemas naturais divididos em: a) sistemas naturais terrestres e b) sistemas naturais marinhos, cada qual com suas subcategorias que abordam características abióticas como: formas de relevo e elementos geológicos, formações e relevos singulares, sistemas cársticos, áreas desérticas ou costeiras, depósitos singulares de origem fluvial e eólica, entre outras (Anexo I da lei). Assim, a amostra mais representativa da geodiversidade dos sistemas naturais pode constituir um Parque Natural, sujeitos pela mesma lei à atenção em relação à sua "conservação, merecendo atenção prioritária e declarada como de interesse geral do Estado". Outro instrumento de proteção dos Parques Naturais está previsto na Ley 42/2007, Art. 30.1, onde um dos critérios para nomear Parque como espaço natural protegido é através da sua diversidade geológica como características principais.

A proteção dos Parques Naturais decorrentes da sua vertente geológica também é prevista na LDSMR, a qual inclui ações para o desenvolvimento rural sustentável. Esta lei também traz uma componente que pode ser entendida como um meio de impulsionar a criação de geoparques, ao declarar no Art. 20.g., que, entre as medidas para desenvolvimento rural sustentável inclui: "medidas para incentivar a diversificação econômica, o uso dos recursos geológicos que existem no meio rural e que podem ser utilizados para um desenvolvimento sustentável, observando como prioridade a conservação do meio ambiente, a paisagem e o patrimônio natural e cultural”. Do mesmo modo, o Art. 20.f., coloca como medida "atividades para informar e formar os habitantes do meio rural sobre a potencialidade de uso do seu Patrimônio Natural e Cultural, propondo iniciativas que facilitem a implantação de um turismo geológico, ecológico, mineiro e outros aproveitamentos culturais". Com clareza percebemos as semelhanças entre os objetivos explicitados na lei e os objetivos de criação de um geoparque, além da implantação da atividade geoturística como um meio de desenvolver sustentável e economicamente uma região. Esta lei entrou em vigência em janeiro de 2008, sendo revisada em outubro de 2009.

Outra lei demasiada importante e que reúne definições acerca do patrimônio geológico e geodiversidade é a LPNB, com vigência da sua última revisão em dezembro de 2013, substitui a Ley 4/1989 de Conservacion de los Espacios Naturales y de la Flora y Fauna Silvestres. A lei traz definições importantes no que tange à conservação da geodiversidade, como: Art. 3.18, define "geodiversidade ou diversidade geológica"; Art. 3.19, "geoparques ou parques geológicos”; apresenta também a diversidade geológica como parte do patrimônio natural (Art. 3.27), geodiversidade como recurso natural (Art. 3.30) e patrimônio geológico (Art. 3.38) (Díaz-Martínez et al., 2008). É interessante notar que, diferentemente da lei brasileira, o Art. 3 da lei espanhola, que versa sobre as definições, especifica geodiversidade separadamente de biodiversidade, esta última definida de acordo com o Art. 3.3 sobre "biodiversidade ou diversidade biológica”. A conservação dos espaços naturais na sua vertente geológica é explícita, prevista conforme:

a) Art. 5.2.f: “A proteção da geodiversidade é um dever das administrações públicas”. Há o comprometimento por parte das autoridades governamentais em proteger o patrimônio geológico, e isto é explícito na legislação.

b) Art.12.1: Prevê a elaboração de um Plano Estratégico do Patrimônio Natural, assumindo o uso sustentável da geodiversidade e conservação da mesma, sendo que o Plano traz como um de seus elementos básicos o diagnóstico e situação dos aspectos geológicos (Art. 12.2).

c) Art. 17: Sobre os Planos de Ordenação dos Recursos Naturais (PORN): b. definir o estado de conservação da geodiversidade; c. identificar a capacidade e estado de conservação dos componentes da geodiver- 
sidade; f. prever e promover a aplicação de medidas e critérios de conservação e restauração da geodiversidade.

d) Art. 22.1 e 22.2: Proíbe alteração dos aspectos físicos que dificulte a implantação do PORN, não poderá ser concedida nenhuma outorga, autorização ou concessão que modifique a realidade geológica.

e) Art. 33.2: Proíbe a coleta de exemplares geológicos ou amostras nas Reservas Naturais (permitida apenas com autorização).

f) Art. 32.1: Figura de proteção dos elementos geológicos do meio marinho - Área Marinha Protegida.

g) Art. 33.3: Figura de Monumento Natural, onde é proibida a exploração dos recursos.

Esta lei também prevê a elaboração do Inventário Español de Lugares de Interés Geológico (Art. 9.2.10). As informações sobre os pontos levantados por projetos anteriores não seguiram um padrão metodológico para tal. Por esta razão, em 2009, García-Cortés \& Carcavilla Urquí, juntamente com o IGME e com a colaboração de outros pesquisadores, propuseram uma metodologia específica para atualizar os pontos de interesse até então levantados, assim como os futuros, em resposta à lei 42/2007 (Carcavilla-Urquí et al., 2011). O documento intitulado Documento Metodológico para la Elaboración del Inventario Español de Lugares de Interés Geológico (IELIG), objetiva primeiramente o levantamento dos Lugares de Interés Geológico (LIGs), onde os pontos seriam avaliados considerando a seguinte classificação: a) Âmbito: regional, nacional, internacional - os de âmbito locais não são objeto do inventário, ficando sobre responsabilidade dos municípios, comarcas, comunidades autônomas ou espaços naturais protegidos; b) Tipologia: estratigráfico, tectônico, geomorfológico, etc.; c) Valores: estabelecidos de acordo com Cendero (1996): Valor intrínseco; Valor ligado à potencialidade de uso; Valor ligado à necessidade de proteção.

\section{Portugal}

As primeiras atividades em Portugal relacionadas à geoconservação tiveram início com a elaboração do projeto "Patrimônio Geológico de Excepcional Valor de Portugal”, por parte da Associação Portuguesa e da Liga para a Proteção da Natureza ou LPN (Ruchkys, 2007), esta última, fundada em 1948 voltada para a defesa do Meio Ambiente e com os objetivos principais de "conservação do Patrimônio Natural, da diversidade das espécies e dos ecossistemas e a defesa do ambiente" (LPN/CAEA, 2012).

Em 1977 é fundado o Centro de Estudos e Atividades Especiais (CAEA) da LPN, um centro de estudo que se dedica às atividades ligadas à natureza, principalmente aquelas relacionadas com a espeleologia, montanhismo, escalada, e etc., possuem caráter recreativo, educacional, científico ou desportivo, mesmo não possuindo um viés de proteção legal dos aspectos naturais, contribui para a divulgação do mesmo, aproximando natureza e especialmente os recursos abióticos dos visitantes. Este centro de estudos apresenta como objetivos a promoção de ações voltadas para a formação, estudo, conservação e usufruto do Patrimônio Natural e Cultural, em particular os meios marinhos, as cavidades naturais, ribeirinho e montanha (LPN/CAEA, 2012).

Um trabalho mais específico de identificação das feições geológicas é apresentado em 2001, baseado nos objetivos e recomendações do projeto Geosites e da ProGEO (Associação Europeia para a Conservação do Patrimônio Geológico), onde foram identificadas as categorias temáticas de relevância internacional ou frameworks, através de uma metodologia proposta da ProGEO (Lima, 2008). Em 2007, o projeto "Identificação, caracterização e conservação do patrimônio geológico: uma estratégia de geoconservação para Portugal”, idealizado pela Universidade do Minho em parceria com outras instituições de ensino e pesquisa, apresenta como objetivo a definição de uma estratégia de geoconservação, colaborando com a divulgação das ciências da Terra, veio refletir em 2008, na legislação portuguesa, que inclui a garantia de proteção aos geossítios e ao patrimônio geológico português (Lima, 2008).

O Decreto-Lei $n^{\circ} 142$ de 24 de julho de 2008, além de prever a proteção das formações geológicas relevantes também faz menção aos geoparques. Entre os objetivos da lei, cabe destacar a promoção da "investigação científica e o conhecimento sobre o patrimônio natural, bem como a monitoração de espécies, habitats, ecossistemas e geossítios”, e a promoção do "conhecimento pela sociedade do valor 
patrimonial, econômico e social da biodiversidade e do patrimônio geológico".

A saber, o Decreto-Lei traz a definição de geossítios, "a área de ocorrência de elementos geológicos com reconhecido valor científico, educativo, estético e cultural" (Art. $3^{0}$, i), e patrimônio geológico, “o conjunto de geossítios que ocorre numa determinada área e que inclui o patrimônio geomorfológico, paleontológico, mineralógico, petrológico, estratigráfico, tectônico, hidrogeológico, pedológico, entre outros" (Art. $\left.3^{\circ}, \mathrm{m}\right)$.

A proteção dos geossítios é prevista no Art. $6^{\circ}$, que trata sobre a conservação da natureza e biodiversidade, através de ações de conservação que correspondem a um conjunto de medidas e ações de intervenção dirigidas ao manejo direto de espécies, habitats, ecossistemas e geossítios, bem como ações de intervenção associadas a atividades socioeconômicas diversas, com implicações significativas no manejo de espécies, habitats, ecossistemas e geossítios, visando sua manutenção ou recuperação para um estado favorável (Art. $6^{\circ}$, a).

O Capítulo II do Decreto-Lei versa sobre o Sistema Nacional de Áreas Classificadas (SNAC), constituído pela Rede Nacional de Áreas Protegidas (RNAP), pela Rede Natura 2000 e pelas demais áreas classificadas ao abrigo de compromissos internacionais assumidos pelo estado Português - as quais incluem os geoparques (Art. $27^{\circ}$, 2.f). Em relação à RNAP, são apresentadas cinco tipologias de classificação das áreas protegidas, de âmbito local, regional ou nacional: Parque Nacional, Parque Natural, Reserva Natural, Paisagem Protegida e Monumento Natural, e todas incluem as feições geológicas relevantes ou geossítios como características contempladas pelas tipologias, além de prever a sua proteção em cada uma delas, como pode ser observado nos Artigos $16^{\circ}$ ao $20^{\circ}$, do referido decreto-lei. O objetivo da classificação das áreas protegidas é a concessão de um estatuto legal de proteção, tanto para a diversidade biológica e ecossistemas, quanto para o patrimônio geológico e paisagens (Art. $12^{\circ}$ ). Conforme o Art. $43^{\circ}$, é constituído como "contra-ordenação ambiental muito grave e punível”, os atos que afetem negativamente as áreas protegidas, especificamente "a destruição ou delapidação de bens culturais inventariados ou geossítios" (Art. 43, 1. q). A coleta de amostra de minerais, rochas e fósseis, também é considerada uma contra-ordenação ambiental leve, mas passível de punição (Art. $43^{\circ}$, 4.h).

O Decreto-Lei ${ }^{\circ} 142$ de 2008 consagra o Sistema de Informação sobre Patrimônio Natural (SIPNAT), constituído pelo inventário da biodiversidade e patrimônio geológico (Art. $28^{\circ}$ ), e o Cadastro Nacional dos Valores Naturais Classificados, um instrumento operacional, com informações sobre os valores naturais classificados ou considerados sob ameaça (Art. $29^{\circ}$ ), o qual também inclui os geossítios.

Posto isto, a legislação portuguesa atual contempla a geoconservação através da proteção dos geossítios e do patrimônio geológico, além de instituir ações de identificação e informação sobre o patrimônio geológico, o que é de suma importância apesar de não trazer definições importantes como geodiversidade e a própria geoconservação.

\section{Brasil}

As primeiras atitudes no Brasil em relação à proteção dos aspectos geológicos remontam da década de 1930 (Pereira, 2010), sendo que o olhar mais atento à divulgação da geodiversidade e sua necessidade de proteção ocorre a partir da instituição da Comissão Brasileira de Sítios Geológicos e Paleobiológicos - SIGEP, que tem por finalidade de identificar, cadastrar e divulgar monumentos naturais de formações geológicas e fisiográficas, além de sítios paleontológicos, cada um destes com um específico valor e singularidade (Schobbenhaus \& Silva, 2010). Contudo a SIGEP não possui um caráter formal, o que impede a implantação de políticas e planejamentos para melhor gestão dos geossítios. Em 2011, foi sugerida a oficialização da SIGEP junto à Presidência da República e, em 2012, foi criado o Grupo de Trabalho Interministerial de Sítios Geológicos e Paleontológicos, por meio da Portaria $\mathrm{n}^{0} 170$, de 20 de junho de 2012, com o intuito de implantar o Marco Legal visando à oficialização da SIGEP.

Dentro do ordenamento jurídico brasileiro, é possível que os lugares de interesse para geoconservação sejam enquadrados e protegidos de acordo com alguns instrumentos jurídicos (Pereira et al., 2008; Mansur, 2010; 
Vilas Boas, 2012). No entanto, estes instrumentos legais conferem uma proteção de maneira secundária, visto que a proteção da geodiversidade não é clara e especificamente abordada em lei alguma.

Os principais elementos legais, os quais podem englobar os recursos geológicos, abordados por Lima (2008), Silva \& Assumpção (2009) e Vilas Boas (2012) são:

a) Decreto-Lei $n^{0} 25$ de 30 de novembro de 1937, que diz respeito às áreas de tombamento, como patrimônio histórico e artístico nacional. De acordo como art. $2^{\underline{0}}$, estão sujeitos a tombamento "os monumentos naturais, bem como os sítios e paisagens que importe conservar e proteger pela feição notável com que tenham sido dotados pela natureza ou agenciados pela indústria humana”.

b) Decreto-Lei ${ }^{\circ} 4.146$ de 4 de março de 1942, que determina a proteção dos depósitos fossilíferos, sendo o único elemento que compõe a geodiversidade e que possui instrumentos de proteção específica e direta e por isso merece atenção. De acordo com o Decreto-Lei citado, a autorização e extração de espécimes fósseis são de responsabilidade do DNPM. Em contrapartida, conforme o DecretoLei ${ }^{\circ} 227$ de 28 fevereiro 1967 compete ao DNPM gerir e fomentar o aproveitamento econômico dos recursos minerais da União. O órgão fica responsável, portanto, em mediar os possíveis conflitos existentes entre a exploração mineral e a proteção de espécimes fósseis.

Em novembro de 1970 a UNESCO promove a "Convenção relativa às medidas a serem adotadas para proibir e impedir a importação, exportação e transferência de propriedades ilícitas dos bens culturais”, os quais incluem os objetos de interesse paleontológico.

Fica estabelecido que os países signatários (dentre eles o Brasil) são responsáveis pela implantação de medidas legais que visam a proteção dos bens culturais, e o Decreto-Lei $n^{\circ}$ 72, de 31 de maio de 1973 promulga a Convenção, anteriormente já aprovada de acordo com o Decreto-Lei $\mathrm{n}^{0} 71$, de 28 de novembro de 1970. A Constituição Federal de 1988 também prevê a proteção de espécimes fósseis, colocando-os como bens culturais conforme Art. 20, I, e repreendendo a comercialização dos mesmos, de acordo com o Art. 23, IV. c) Lei $\mathrm{n}^{0} 4.771$ de 15 de setembro de 1965, revogada pela Lei $\mathrm{n}^{0} 12.651$, de 25 de maio de 2012, na qual é prevista a proteção das APP (Áreas de Preservação Permanente), e cita os recursos abióticos: “área protegida, coberta ou não por vegetação nativa, com a função ambiental de preservar os recursos hídricos, a paisagem, a estabilidade geológica e a biodiversidade, facilitar o fluxo gênico de fauna e flora, proteger o solo e assegurar o bem-estar das populações humanas” Art. $3^{\circ}$, II da mesma Lei.

d) Lei $n^{0} 9.985$, de 18 de julho de 2000, que institui o SNUC - Sistema Nacional de Unidades de Conservação. Esta Lei se apresenta como uma das principais ferramentas para geoconservação que engloba dois grupos de Unidades de Conservação (UC), subdivididas em 12 categorias de manejo com objetivos distintos e regras próprias em relação à pesquisa científica, posse da terra e uso.

Pereira et al. (2008) especificam as possibilidades de enquadramento da proteção da geodiversidade no SNUC, mas ressaltam que esta lei está centrada essencialmente na proteção da biodiversidade. De acordo com os autores, as principais categorias de manejo dentro do SNUC entre as quais pode ser enquadrada a proteção do patrimônio geológico são: Parque Nacional, Monumento Natural, Área de Proteção Ambiental, Área de Relevante Interesse Ecológico, Reserva Extrativista, Reserva de Desenvolvimento Sustentável, Reserva Particular do Patrimônio Natural.

Estas categorias possuem objetivos semelhantes aos objetivos da geoconservação e da proteção dos geossítios, como o incentivo à educação ambiental, pesquisa científica, atividades turísticas e recreativas e desenvolvimento econômico sustentável.

Para os autores, dentre as categorias apresentadas, Monumento Natural é a que melhor se enquadra na proteção dos recursos abióticos, pois tem como objetivo a "preservação de sítios raros, singulares e/ou de grande beleza cênica”.

Se por um lado o SNUC deixa a desejar quanto à abordagem tímida em relação à relevância e proteção do patrimônio geológico, esta mesma lei constitui uma das principais ferramentas encontradas no ordenamento jurídico brasileiro que remete à geoconservação (Pereira et al., 2008). 
É ainda "um recurso pouco utilizado, uma vez que a grande maioria das UCs foi criada com foco na proteção da biodiversidade, colocando a geodiversidade em segundo plano'. (...) 'contudo, compõe um recurso essencial para implantar a geoconservação no país” (Pereira, 2010). Estes aspectos refletem a carência de ações e iniciativas com bases legais para a proteção do patrimônio geológico brasileiro.

Existem no Brasil, centenas de unidades de conservação que, de acordo com o Cadastro Nacional de Unidades de Conservação (CNUC), até julho de 2017 somam 2.100 UCs.

Como aborda Nascimento (2010), a grande maioria dos Parques Nacionais tem como principais atrativos os aspectos geológicos, mas estes recursos não são olhados com as devidas atenções. Mesmo o patrimônio geológico sendo o ponto central da maioria dos Parques
Nacionais, por exemplo, o SNUC, que se apresenta como uma das principais ferramentas para proteger o patrimônio geológico dentro do ordenamento jurídico brasileiro, não especifica este tipo de proteção (Nascimento, 2010).

Com vistas à análise da legislação apresentada, Pereira (2010) aborda a importância de futuras revisões de leis que foquem em questões ambientais e de conservação da natureza no Brasil, para que passem a contemplar as necessidades e especificidades inerentes da geodiversidade e do patrimônio geológico.

Com base no que foi apresentado, o quadro 1 apresenta uma síntese das principais leis que visam à proteção dos componentes abióticos nos países em questão, e evidencia a forma de abordagem de termos importantes em cada um deles, como geodiversidade, patrimônio geológico e geoconservação.

\section{DISCUSSÃO DOS RESULTADOS}

É possível observar que os países europeus citados apresentam grande avanço no que concerne à proteção do patrimônio geológico, primeiramente por utilizarem terminologias específicas para se referir à biodiversidade e geodiversidade separadamente.

Neste ponto, pode-se verificar que os recursos abióticos são mencionados pelas suas características intrínsecas e particulares, e não como apenas um substrato indissociável dos recursos bióticos, como observado na legislação brasileira (Figura 1).

A legislação dos países da Grã-Bretanha apesar de não fazer menção a conceitos específicos como patrimônio geológico ou geoconservação, traz uma diferenciação importante entre a biodiversidade e a geodiversidade. A partir desta diferenciação, há tratamentos característicos para ambos, inclusive em relação à proteção dos sítios geológicos.

Há uma boa proposta de classificação dos sítios, dividindo-os em sítios locais (LGAPS), sítios regionais (RIGS), sítios de especial interesse científico (SSSIs) e áreas de proteção especiais (SPAs), e definindo ações de proteção que são específicas para cada uma das categorias. A participação de autoridades na proteção dos sítios também é prevista em lei.
A Espanha mostrou-se o país que apresenta a legislação mais completa considerando a temática da geoconservação como um todo.

As leis: Ley 5/2007, Ley 45/2007 e Ley 42/2007 são complementares, trazem definições sobre conceitos indissociáveis como geodiversidade, patrimônio geológico, geoconservação e também geoparques. São leis que preveem a criação de áreas protegidas a partir dos recursos geológicos, com medidas específicas para tal.

Outra questão bastante interessante, é a Ley 45/2007 que, apesar de não especificar o termo geoturismo, apresenta a mesma proposta de utilizar os recursos geológicos como atrativos turísticos e como um meio de desenvolvimento econômico para a população. Esta lei claramente facilita a criação de geoparques, pois já prevê em lei a realização de atividades características dos mesmos. Portugal possui o SNAC, com categorias de proteção bastante semelhantes àquelas contidas no SNUC brasileiro (Lei $\mathrm{n}^{0}$ 9.985 de 2000).

No entanto, o Decreto-Lei ${ }^{0} 142$ de 2008 de Portugal, o qual institui o SNAC, distingue biodiversidade de patrimônio geológico, conferindo características próprias às categorias relacionadas à vertente geológica e sua proteção. 


\begin{tabular}{|c|c|c|}
\hline Países & Principais leis de proteção & Forma de abordagem \\
\hline Brasil & $\begin{array}{l}\text {-Decreto Lei ñ } 25 \text { de 1937: sobre Áreas de Tombamento } \\
\text {-Decreto Lei nº } 4146 \text { de 1942: sobre proteção dos depósitos } \\
\text { fossilíferos. } \\
\text {-Lei nº 9.985 de 2000: SNUC, nas categorias: Parque Nacional, } \\
\text { Monumento Natural, APA, ARIE, ReEx, Reserva Desenvolvimento } \\
\text { Sustentável, RPPN. } \\
\text {-Lei nº } 12651 \text { de 2012: sobre proteção das APP’s. }\end{array}$ & $\begin{array}{l}\text {-Indireta: não são definidos os } \\
\text { termos geodiversidade, } \\
\text { patrimônio geológico ou } \\
\text { geoconservação. } \\
\text {-Não há distinção clara entre } \\
\text { geodiversidade e biodiversidade. }\end{array}$ \\
\hline $\begin{array}{c}\text { Grã- } \\
\text { Bretanha }\end{array}$ & $\begin{array}{l}\text {-Art. } 28 \text { do Wildlife and Countryside Act 1981: sobre a proteção } \\
\text { dos SSSIs. } \\
\text {-Parte II do Planning Policy Statement 9: sobre os SSSIs. } \\
\text {-Countryside and Rights of Way Act 2000: sobre proteção dos sítios } \\
\text { geológicos. } \\
\text {-Parte I do Planning Policy Statement 9: sobre as potenciais Áreas } \\
\text { de Proteção Especial (SPAs). }\end{array}$ & $\begin{array}{l}\text {-Direta: há diferenciação entre } \\
\text { biodiversidade e geoconservação. } \\
\text { - É prevista proteção específica } \\
\text { para os sítios de interesse } \\
\text { geológico. }\end{array}$ \\
\hline Espanha & $\begin{array}{l}\text {-Ley 5/2007: instaura a Rede de Parques Nacionais, podem ser } \\
\text { criados a partir de uma amostra representativa da geodiversidade. } \\
\text {-Ley 45/2007: LDSMR, sobre desenvolvimento sustentável em } \\
\text { áreas rurais e prevê medidas de implantação do geoturismo. } \\
\text {-Ley 42/2007: LPNB traz definições específicas sobre a temática, } \\
\text { prevê medidas de proteção e a implantação de inventário nacional. }\end{array}$ & $\begin{array}{l}\text {-Direta: são definidos em lei os } \\
\text { termos geodiversidade, } \\
\text { geoconservação, patrimônio } \\
\text { geológico, geoparques. } \\
\text {-A lei difere geodiversidade de } \\
\text { biodiversidade. }\end{array}$ \\
\hline Portugal & $\begin{array}{l}\text {-Decreto Lei } \mathrm{n}^{0} 142 \text { de 2008: prevê proteção das formações } \\
\text { geológicas. Institui o SNAC, que contempla em todas as categorias } \\
\text { as feições geológicas ou geossítios e sua proteção. }\end{array}$ & $\begin{array}{l}\text {-Direta: há definições sobre } \\
\text { geossítio, patrimônio geológico e } \\
\text { a lei também faz menção aos } \\
\text { geoparques. } \\
\text { - Não define geodiversidade ou } \\
\text { geoconservação. } \\
\text {-Há separação entre elementos } \\
\text { abióticos e biodiversidade. }\end{array}$ \\
\hline
\end{tabular}

Figura 1 - Comparativo entre a abordagem da geoconservação nas leis nacionais e internacionais.

Tanto Grã-Bretanha quanto os países ibéricos apresentam definições de conceitos importantes que asseguram diretamente a integridade dos sítios geológicos, como geodiversidade e/ou patrimônio geológico, não deixando margens para interpretações das leis. A título de exemplo, supõe-se que em uma disputa judicial venha a ocorrer conflitos de interesse entre a geoconservação e ações por parte de qualquer empreendimento (minerações, obras de infraestrutura, loteamentos, etc.). Nas leis internacionais, está bem conceituado o que é patrimônio geológico, o que é geodiversidade, e sob quais leis ele deve ser protegido. Na legislação brasileira, a interpretação do que é patrimônio geológico depende de observações secundárias sobre os recursos abióticos, provocando uma insegurança jurídica quanto à proteção dos mesmos frente às ameaças. Outro ponto interessante das leis internacionais é o levantamento dos sítios geológicos anteriormente à proposição legal, conforme previsto em lei ou em planos específicos: os SSSIs na Grã-Bretanha, os LIGs na Espanha e os frameworks em Portugal. É primeiramente realizada a caracterização dos sítios geológicos conforme metodologias pré-definidas, e posteriormente é instituída a proteção, de acordo com as necessidades de cada área.

No Brasil, os únicos componentes da geodiversidade que recebem específica menção e proteção legal são os depósitos fossilíferos. Os trabalhos de Rocha-Campos (2000), Geisicki \& Santucci (2011) e Vilas Boas (2012), discutem casos brasileiros os quais estão vinculados especialmente à presença de objetos paleontológicos em áreas mineradas ou antigas minerações, e sua proteção frente à ameaça de exploração mineral é resultado dos instrumentos legais que preveem a proteção dos espécimes fósseis. Neste contexto, assim como é especificamente prevista em lei a proteção dos depósitos fossilíferos, devem ser asseguradas e definidas legalmente a proteção de outras tipologias patrimoniais da vertente geológica, para que sua proteção seja efetivamente assegurada. Com igual importância merece atenção em lei a definição de terminologias que, ao exemplo internacional, 
asseguram o entendimento e proteção de elementos da vertente geológica, como geodiversidade, geossítios, geoconservação, geoturismo e patrimônio geológico.

Sendo assim, percebe-se que as leis brasileiras mesmo possuindo instrumentos que possibilitam 0 enquadramento da geodiversidade, encontram-se defasadas quando comparadas às leis internacionais em relação ao assunto e deixam muito a desejar. Por esta razão, faz-se necessária uma revisão legislativa que contemple diretamente a proteção dos recursos abióticos, e que paralelamente impulsione a criação de novos geoparques no país.

Como já foi mencionada a proteção dos geossítios é um requisito importante para a chancela de um Geoparque. Se o sítio geológico possui valores relevantes e deve ser protegido, as leis internacionais citadas asseguram sua proteção sem maiores questionamentos, ou melhor, proteger os afloramentos geológicos é cumprir a lei, simplesmente. Notoriamente deve haver estudos precedentes sobre as carac- terísticas e relevância destes locais, mas após esta etapa de investigação as leis já se encontram à espera para serem aplicadas.

Desta maneira é possível estabelecer um paralelo entre as medidas legais de geoconservação e a chancela de geoparques. Para sustentar esta afirmação, pode-se verificar a quantidade de geoparques existentes nos países mencionados. Primeiramente Portugal que possui em seu território quatro Geoparques. A Grã-Bretanha (Inglaterra, País de Gales e Escócia) soma nove Geoparques, e Espanha, dez. O Brasil, um país territorialmente mais extenso e que comporta uma riqueza geológica tão exuberante e representativa como qualquer outra localidade, possui apenas um Geoparque formalizado pela UNESCO. Neste ponto, perde-se muito com uma legislação incompleta, pois a iniciativa de criação dos geoparques, além de procurar salvaguardar os registros importantes sobre a memória da Terra, também está atrelada a uma proposta de desenvolvimento econômico e social voltada para a população.

\section{CONCLUSÕES}

Em suma, existe uma dificuldade em proteger os recursos geológicos pela sua relevância intrínseca, pelo seu valor científico ou estético, pois estes são valores subjetivos e difíceis de serem mensurados economicamente. No entanto, a incapacidade de perceber na vertente abiótica da natureza um valor singular e insubstituível, não justifica a depreciação irrefreável dos mesmos.

Por estas razões, faz-se urgente uma revisão no ordenamento jurídico brasileiro para que a exemplo dos países europeus comecem a valorizar a riqueza geológica nacional e a protegê-la quando necessário, abandonando o papel de simples substrato da biodiversidade no qual as leis se referem à geodiversidade.

Sendo assim, é possível assegurar para as gerações futuras os registros evolutivos do nosso planeta com a efetiva proteção dos seus geossítios.

É correto dizer que, a chancela de novos Geoparques não depende apenas da proteção legal dos geossítios e que existem inúmeras outras dificuldades encontradas pelas administrações dos mesmos no Brasil. Mas, sendo o patrimônio geológico o ponto primordial de um geoparque, assegurar sua proteção perante a lei é indiscutível.

Como uma sugestão importante é recomendada a definição de terminologias junto às leis nacionais que conceituem termos como geodiversidade, geoconservação e patrimônio geológico, a fim de melhor estabelecer sistemas de proteção legais direcionados especificamente para os elementos abióticos da natureza.

\section{AGRADECIMENTOS}

Agradecemos à CAPES pela bolsa concedida durante o período de mestrado.

\section{REFERÊNCIAS}

BOGGIANI, P.C.A aplicação do conceito de Geoparque da UNESCO no Brasil e relação com o SNUC - Sistema Nacional de Unidades de Conservação. Revista eletrônica

Patrimônio Geológico e Cultura, v. 1, n. 1, 2009.

BRASIL. Decreto-lei $n^{\circ}$ 25, de 30 de novembro de 1937.
Organiza a proteção do patrimônio histórico e artístico nacional. Brasília, DF, 1937. Disp. em: http://www.planalto. gov.br/ccivil_03/decreto-lei/del0025.htm.

BRASIL. Decreto-lei $n^{\circ}$ 4.146, de 4 de março de 1942. Dispõe sobre a proteção dos depósitos fossilíferos. Brasília, DF, 
1942. Disp.em: http://www.planalto.gov.br/ccivil_03/decretolei/1937-1946/Del4146.htm.

BRASIL. Lei $\mathbf{n}^{\circ}$ 12.651, de 25 de maio de 2012. Dispõe sobre a proteção da vegetação nativa; altera as Leis nos 6.938, de 31 de agosto de 1981, 9.393, de 19 de dezembro de 1996, e 11.428, de 22 de dezembro de 2006; revoga as Leis nos 4.771, de 15 de setembro de 1965, e 7.754, de 14 de abril de 1989, e a Medida Provisória no 2.166-67, de 24 de agosto de 2001; e dá outras providências. Brasília, DF, 2012. Disp.: http://www.planalto.gov.br/ccivil_03/_ato2011-

2014/2012/lei/l12651.htm

BRASIL. Lei $\mathbf{n}^{\circ} \mathbf{6 . 9 3 8}$, de 31 de agosto de 1981. Dispõe sobre a Política Nacional do Meio Ambiente, seus fins e mecanismos de formulação e aplicação, e dá outras providências. Brasília, DF, 1981. Disp. em http://www.planalto.gov.br/ccivil_03/leis/16938.htm.

BRASIL. Lei $\mathbf{n}^{\circ} \mathbf{9 . 9 8 5}$, de 18 de julho de 2000. Regulamenta o art. 225, § 1o, incisos I, II, III e VII da Constituição Federal, institui o Sistema Nacional de Unidades de Conservação da Natureza e dá outras providências. Brasília, DF, 2000. Disp. em: http://www.planalto.gov.br/ccivil_03/leis/19985.htm.

Brilha, J. Património Geológico e Geoconservação: a Conservação da Natureza na sua Vertente Geológica. Braga, Palimage, 190p., 2005.

CARCAVILLA-URQUÍ, L.; DÍAZ-MARTINEZ, E.; GARCÍA-CORTÉS, Á.; VEGAS, J. Legislación para el inventário de lugares de interés geológico em las comunidades autônomas. Avances y Retos em la Conservación del Patrimonio Geologico em España. In: REUNIÓN NACIONAL DE LA COMISSION PATRIMONIO GEOLOGICO, XI. Anais...Dinópolis, p. 56 - 61, 2011.

CENDERO, A. El patrimonio geológico. Ideas para suprotección, conservación y utilización. In: El patrimônio geológico. Bases para suvaloración, protección, conservación y utilización. Ministério de Obras Publicas, Transportes y Medio Ambiente - MOPTA. Madrid, p. $17-38,1996$.

DCLG. Departament for Communities and Local Government Framework. 2012. National Planning Policy Framework. London, DCLG, 65p. Disp.: < https://www.gov.uk/

government/uploads/system/uploads/attachment_data/file/6077/ 2116950.pdf $>$. Acesso em: 24 de agosto de 2014.

DÍAZ-MARTÍNEZ, E., GUILLÉN-MONDÉJAR, F., MATA, J.M., MUÑOZ, P., NIETO, L., PÉREZ-LORENTE, F.; SANTISTEBAN, C. D. Nueva legislación española de protección de la Naturaleza y desarrollo rural: implicaciones para la conservación y gestión del patrimonio geológico y la geodiversidad. In: CONGRESO GEOLÓGICO NACIONAL, 2008. Madrid. Anais...Madrid: Sociedad Geológica de España, v. 1, p. 1307-1310, 2008.

ELLIS, N. Geoconservation work within JNCC - a forward look to 2011 and beyond. England/JNCC, 11p. 2008. Disp.: $<$ http://www.jncc.gov.uk/PDF/comm08D05.pdf >. Acesso em: 11 de abril de 2014

ELLIS, N.V.; BOWEN, D.Q.; CAMPBELL, S.; KNILL, J.L.; MCKIRDY, A.P.; PROSSER, C.D.; VINCENT, M.A.; WILSON, R.C.L. Contents of Na Introduction to the Geological Conservation Review. 2008. Join Nature Conservatio Comittee. Disp.: <http://www.jncc.gov.uk/page2965>. Acesso em: 29 de março de 2014.

ESPANHA. Ley 16/1985 delPatrimonio Histórico Español. 25 de junho de 1985. Disp.: https://www.boe.es/buscar/act. php?id=BOE-A-1985-12534.

ESPANHA. Ley $\mathbf{4 2 / 2 0 0 7}$ delpatrimonio natural y labiodiversidad. 14 de dezembro de 2007. Disp.: https://www.boe.es/buscar/act.php?id=BOE-A-2007-21490.

ESPANHA. Ley 45/2007 para el desarrollo sostenible del medio rural. 13 de dezembro de 2007. Disp. em: https://www.boe.es/buscar/act.php?id=BOE-A-200721493.
ESPANHA. Ley 5/2007 de laRed de Parques Nacionales. 3 de abril de 2007. Disp. em: https://www.boe.es/buscar/act. php?id=BOE-A-2007-7108.

GARCÍA-CORTÉZ, A. \& CARCAVILLA-URQUÍ, L. Documento metodológico para elaboracióndel inventário español de lugares de interés geológico (IELIG). Madrid, Instituto Geologico y Minero de España, 61p., 2009.

GRAY, M. Geodiversity: valuing ang conserving abiotic nature. London, John Wiley \& Sons. 450p., 2004

HAFFEY, D. Local Geodiversity Action Plans: A review of progress in England. Peterborough, Natural England Research Reports, 94p. 2008. Disp. em: http://publications.naturalengland.org.uk/publication/36005?c ategory $=30050>$. Acesso em 18 de julho de 2014 .

JNCC. Join National Conservation Committee. 1977. Guidelines for Selection of Earth Science SSSIs. Great Britain, JNCC, 11p. Disp. em: < http://jncc.defra.gov.uk/pdf/ earthscienceSSSI.pdf $>$. Acesso em 24 de agosto de 2014.

LIMA, F.F. Proposta Metodológica para Inventariado do Patrimônio Geológico Brasileiro. Braga, 2008. 103p. Dissertação (Mestrado), Departamento de Ciências da Terra, Universidade do Minho.

LPN/CAEA. Liga para proteção da natureza/Centro de estudos e atividades especiais. 2012. Disponível em: $<$ http://www.lpn-espeleo.org/>. Acesso em: 27 de outubro de 2014.

MANSUR, K.L. Diretrizes para Geoconservação do Patrimônio Geológico do Estado do Rio de Janeiro. O Caso do Domínio Tectônico Cabo Frio. Rio de Janeiro, 2010. 277p. Tese (Doutorado), Instituto de Geociências, Universidade Federal do Rio de Janeiro.

NASCIMENTO, M.A.L. Diferentes ações a favor do patrimônio geológico brasileiro. Estudos Geológicos, v. 20, n.2, p. 81-92, 2010

ODPM. Office of the Departament Prime Minister. 2005. Circular 06/2005. Government Circular: Biodiversity And Geological Conservation - Statutory Obligations And Their Impact Within The Planning System. London, 88p. Disp. em: <http://webarchive.nationalarchives.gov.uk

/20120919132719/http://www.communities.gov.uk/document s/planningandbuilding/pdf/147408.pdf $>$. Acesso em 23 de agosto de 2014

PEREIRA, R.G.F.A. Geoconservação e desenvolvimento sustentável na Chapada Diamantina (Bahia-Brasil). Braga, 2010. 318p. Tese (Doutorado), Programa de Pósgraduação em Patrimônio Geológico e Geoconservação, Departamento de Ciências da Terra, Universidade do Minho.

PEREIRA, R.G.F.A., BRILHA, J. \& MARTINEZ, J.E. Proposta de enquadramento da geoconservação na legislação ambiental brasileira. Publicações do Museu e Laboratório Mineralógico e Geológico da Universidade de Coimbra Memórias e Notícias, v. 3, p. 491-499, 2008.

PORTUGAL. Decreto-lei $\mathbf{n}^{\circ} 142$ de 24 de julho de 2008 Disp. em: http://www.progeo.pt/pdfs/DL_142_08.pdf.

PROSSER, C.; MURPHY, M.; LARWORD, J. Geological conservation a guide to good pratice. Peterborough, Englisj Nature, 2006

ROCHA-CAMPOS, A.C. Varvito de Itu, SP. Registro clássico de glaciação neopaleozóica. Sítios Geológicos e Paleontológicos do Brasil. Brasília: DNPM BRASIL. Departamento Nacional de Produção Mineral (DNPM)/Serviço Geológico, 2002.

RUCHKYS, U.A. Patrimônio Geológico e Geoconser-vação do Quadrilátero Ferrífero, Minas Gerais: Potencial para Criação de um Geoparque da UNESCO. Belo Horizonte, 2007, 211p. Tese (Doutorado em Geologia), Instituto de Geociências, Universidade Federal de Minas Gerais.

SCHOBBENHAUS, C. \& SILVA, C.R. O papel indutor do Serviço Geológico do Brasil na criação de geoparques. Rio de Janeiro, CPRM, 2010, 23p. Disp. em: 
<sigep.cprm.gov.br/destaques/Schobbenhaus_Silva_2

010.pdf $>$. Acesso em 15 de Julho de 2014.

SILVA, N. M. \& ASSUMPÇÃO, F. A. M. E. S. G. Geoparque em área de mineração e o ordenamento jurídico brasileiro. In: CONGRESSO NACIONAL DE PESQUISA EM PÓSGRADUAÇÃO, XVIII, Maringá, 2009. Anais...Maringá: CONPEDI.

UKRIGS. United Kingdom Regionally Important Geological Sites. 2009. Disp.em: <http://wiki.geoconservationuk.org.uk/ index.php5?title=RIG.

UNESCO. United Nations Educational, Scientific and Cultural Organization. Guidelines and Criteria for National Geoparks seeking UNESCO's Assistance to join the Global Geoparks Network (GGN). 2014. Disp. em: <http://www.unesco.org/science/earthsciences/geoparqks/geo parks.htm>. Acesso em: 07 de outubro de 2014.

UNITED KINGDON. Wildlife and Countryside Act 1981. Disp. em: < http://www.legislation.gov.uk/ukpga/1981/69/ contents>. Acesso em 23 de agosto de 2014.

UNITED KINGDON. Countryside and Rights of Way Act 2000. Disp.: http://www.legislation.gov.uk/ukpga/2000/ 37/pdfs/ukpga_20000037_en.pdf. Acesso em 23 de agosto de 2014.

UNITED KINGDOM. Planning Policy Statement 9: biodiversity and geological conservation. 2005. Disp. em: http://www.planningportal.gov.uk/planning/planningpolicyan dlegislation/previousenglishpolicy/ppgpps/pps9. Acesso em 23 de agosto de 2014.

VILAS BOAS, M.P. Patrimônio paleontológico do Geopark Araripe (Ceará - Brasil): análise e propostas de conservação. Braga, 2012. 181p. Dissertação (Mestrado), Departamento de Ciências da Terra, Universidade do Minho.

Submetido em 6 de março de 2016 Aceito em $1^{\circ}$ de agosto de 2017 